\title{
DIGITALISASI POTENSI ASLI DESA DAYEUHMANGGUNG DALAM MENINGKATKAN PENDAPATAN ASLI DAERAH (PAD) BERBASIS WEBSITE
}

\author{
Gunawan $^{1}$, Gunawansyah ${ }^{2}$, Riffa Haviani Laluma ${ }^{3}$, Djoko Pitoyo ${ }^{4}$ \\ 1,2,3,4 Fakultas Teknik, Universitas Sangga Buana \\ ${ }^{1}$ korespondensi : gsyahbdg@gmail.com
}

\begin{abstract}
ABSTRAK
Dayeuhmanggung merupakan sebuah desa yang terletak di Kecamatan Cilawu, Kabupaten Garut, Propinsi Jawa Barat. Memiliki jumlah warga sebanyak 4607 warga atau $1.323 \mathrm{KK}$ dengan mata pencaharian terbesar adalah buruh harian, pegawai BUMD, pengrajin dan pedagang. Desa yang memiliki potensi keindahan alam dan UMKM yang sangat besar, namun belum bisa memaksimalkan potensi tersebut karena keterbatasan dalam hal promosi desa. Penguasaan dan pemanfaatan perkembangan teknologi menjadi salah satu solusi yang bisa di manfaatkan dengan baik karena bisa memberikan dampak yang sangat besar khususnya dalam penggunaan website dan media sosial. Media promosi yang sangat murah, tanpa batasan jarak dan waktu. Solusi promosi potensi desa dan produk UMKM dalam sebuah website dapat memberikan keuntungan ganda bagi desa dan UMKM sehingga bisa memasarkan dan menjalin kerjasama dengan para pembeli dan investor sehingga bisa meningkatkan pendapatan asli desa.
\end{abstract}

Kata Kunci : Promosi , UMKM, Website, Desa Dayeuhmanggung

\begin{abstract}
Dayeuhmanggung is a village located in Cilawu Subdistrict, Garut Regency, West Java Province. It has 4607 residents or 1,323 families with the largest livelihoods being laborers, BUMD employees, craftsmen and traders. A Villages that have very large potential of scenery and UMKM, but have not been able to maximize this potential due to limitations in terms of village promotion. Mastery and utilization of technological developments is one solution that can be put to good use because it can have a very large impact, especially in the use of websites and social media. Very cheap promotional media, without distance and time restrictions. The solution for promoting village potential and UMKM products on a website can provide double benefits for villages and UMKM so that they can sell and collaborate with buyers and investors so that they can increase the village's original income.
\end{abstract}

Keywords: Promotion, UMKM, website, dayeuhmanggung village.

\section{PENDAHULUAN}

Revolusi industri 4.0 berkembang sangat cepat dan memiliki dampak yang sangat besar di Indonesia. Teknologi informasi dan komunikasi (TIK) sebagai salah satu produknya saat ini telah menyentuh semua aspek kehidupan masyarakat baik di perkotaan maupun pedesaan dan salah satu desa yang terdampak adalah desa Dayeuhmanggung.
Dayeuhmanggung merupakan sebuah desa yang terletak di Kecamatan Cilawu, Kabupaten Garut, Propinsi Jawa Barat. Desa yang memiliki 4607 warga dan meliputi 1.323 KK. Jumlah penduduk dengan mata pencaharian terbesar yaitu buruh harian, pegawai BUMD, pengrajin dan pedagang. Desa Dayeuhmanggung memiliki potensi yang beragam dan unik khususnya potensi Usaha Mikro Kecil dan Menengah (UMKM) 
yaitu penggilingan teh, pabrik dodol, pabrik moci, pabrik terasi, pabrik tahu, pembuatan kue, siomay dan ketan serundeng. UMKM tersebut sudah lama berkembang dan mampu menyerap lapangan kerja yang cukup banyak di desa Dayeuhmanggung. cara komunikasi, maupun jarak yang jauh. Sebuah media berbasis internet yang banyak dimanfaatkan untuk pertukaran informasi, komunikasi, hiburan, transaksi bisnis dan promosi. Datanya diletakkan dalam sebuah server atau hosting dan bisa diakses kapanpun,

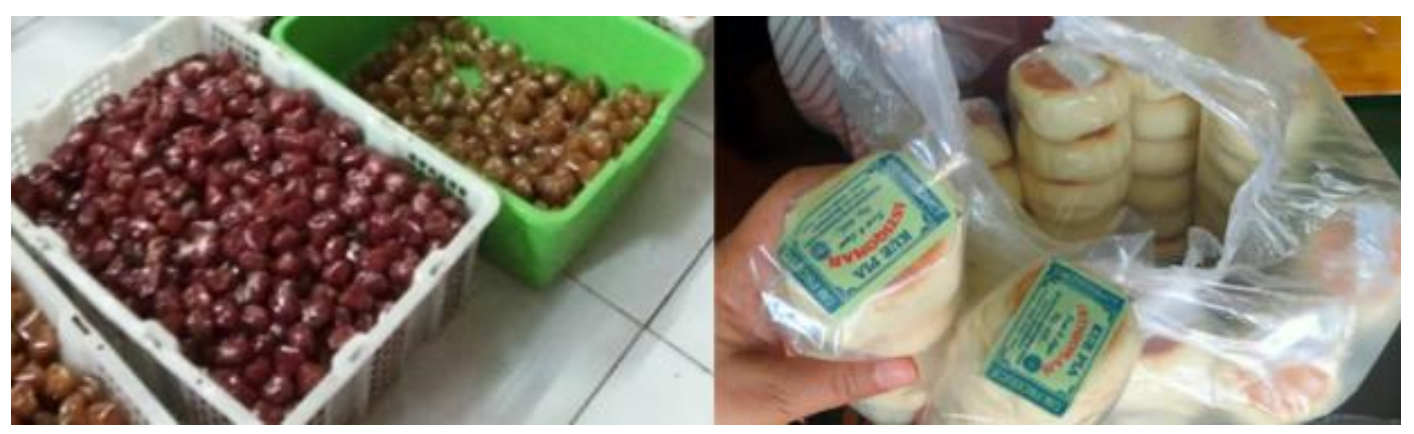

Gambar 1: Produk UMKM

Perkembangan informasi mengenai potensi desa khususnya keindahan alam gunung Cikuray dan produk UMKM saat ini masih sangat terbatas sehingga belum dikenal oleh masyarakat luas. Seiring perkembangan teknologi para pelaku pasar mulai berpindah ke berbagai media yang lebih interaktif dan kekinian dalam mempromosikan dan memasarkan produknya seperti menggunakan website, media sosial, smart phone,games, iklan di adwords dan yang lainnya[1].

Era industri 4.0 membuat peranan website semakin penting karena menjadi salah satu media transaksi dan promosi barang dan jasa yang sangat besar pada saat ini. Berbagai perusahaan, UMKM maupun perorangan berlomba menarik perhatian pelanggan agar belanja dengan menyediakan produk dan pelayanan yang prima. Website menjadi salah satu cara yang efektif dan efisien dalam membuka peluang dan pasar baru yang belum terbuka karena keterbatasan waktu, biaya, dari manapun tanpa batasan jarak dan waktu.[2].

Pembangunan website dengan menampilkan profil lengkap desa dan UMKM yang ada di Desa Dayeuhmanggung merupakan cara yang tepat saat ini agar informasi terkait dengan potensi desa dan UMKM dapat dengan mudah diakses sehingga bisa dikenal oleh masyarakat luas sehingga bisa meningkatnya penghasilan masyarakat Desa Dayeuhmanggung. Semakin meningkatnya kegiatan ekonomi dan transaksi bisnis di harapkan bisa memberikan dampak positif terhadap kesejahteraan masyarakat dan akhirnya bisa meningkatkan Pendapatan Asli Daerah (PAD).

PAD merupakan penerimaan yang diperoleh daerah dari sumber-sumber dalam wilayahnya sendiri yang dipungut berdasarkan peraturan daerah sesuai dengan peraturan perundangundangan yang berlaku[3]. Pendapatan daerah berasal dari pendapatan asli daerah, 
dana Perimbangan, pinjaman daerah dan pendapatan daerah lain-lain yang sah[4].

Pada saat ini UMKM menjadi salah satu andalan dan pilihan para pelaku usaha serta cukup mendominasi perekonomian di Indonesia. Keberpihakan pemegang kebijakan terhadap UMKM harus sudah menjadi prioritas khususnya dalam menghadapi era industri 4.0 yang sedang berjalan saat ini. membuat sebuah website yang berisi profil desa dan pasar digital untuk memasarkan produk-produknya yang selama ini hanya dilakukan melalui telepon.

Pengguna website mencari suatu informasi atau konten dengan mengakses menggunakan apliksi web browser seperti Google Chrome, Safari, Internet Explorer, opera mini dan sebagainya melalui alamat URL website
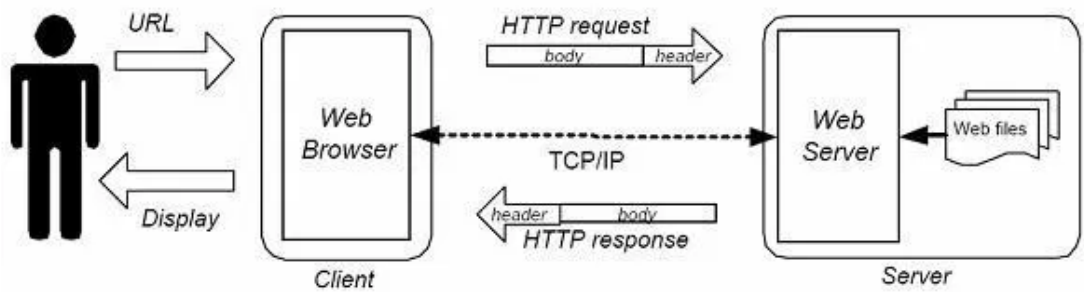

Gambar 2: Cara Kerja Website

Pemanfaatan TIK dalam menunjang berbagai kegiatan bisnis khususnya dalam menyikapi perubahan perilaku konsumen yang mulai bergeser dari model konvensional ke digital termasuk pengambilan keputusan dalam melakukan berbagai transaksi pembelian mulai di lakukan oleh UMKM. Transformasi berbagai media bisnis kearah digital menghendaki adaptasi yang cepat dari para pelaku bisnis khususnya UMKM yang baru mulai atau berkembang. Hal ini menjadi sebuah tantangan sekaligus peluang usaha yang cukup menjanjikan bagi UMKM di Indonesia.

Dalam rangka mendorong digitalisasi dan mempermudah UMKM di desa Dayeuhmanggung dalam menghadapi berbagai perubahan yang terjadi, Fakultas Teknik Universitas Sangga Buana memfasilitasi desa dan para UMKM dengan tersebut. Selanjutnya web browser akan mengirimkan permintaan tersebut ke web server melalui layer-layer TCP/IP dan jika informasi yang diminta tersedia maka web server akan memberikan respon melalui layerlayer TCP/IP dan mengirimkan web file tersebut serta selanjutnya akan di terima oleh web browser untuk di tampilkan di layar pengguna. Apabila informasi yang di cari tidak ada maka web browser akan menampilkan informasi kalau alamat yang di cari tidak tersedia dan tidak bisa diakses oleh pengguna.

\section{METODE}

Metode dalam pembuatan suatu sistem khususnya website digunakan untuk mempermudah dalam proses perancangan sampai evaluasi. 
Kegiatan ini dilaksanakan mulai dari mengumpulkan data, merancang tampilan sampai kepada pembuatan dan pengujian program. Pembuatan sistem informasi menggunakan metode web engineering. [5]

Tahapan-tahapan dalam metode web engineering yang dilaksanakan di desa Dayeuhmangung adalah sebagai berikut :

\section{Customer Communication}

Komunikasi pelanggan memiliki dua tugas pokok yaitu dan analisis bisnis dan perumusan/formulation.

\section{Planning}

Perencanaan merupakan sebuah kegiatan yang terdiri dari definisi dan deskripsi tugas, batas waktu akhir pelaksanaan masing-masing tugas, batas akhir jadwal untuk periode waktu yang ditentukan dalam pembuatan sebuah aplikasi website.

3. Modeling

Modeling merupakan sebuah kegiatan yang dilakukan untuk menentukan semua persyaratan-persyaratan teknis dan mengidentifikasi informasi apa saja yang akan ditampilkan pada sebuah aplikasi berbasis website. Bertujuan untuk membangun analisis yang cepat dan desain model yang menggambarkan kebutuhan. Pemodelan dibagi menjadi dua tahapan yaitu model analisis, terdapat lima aspek yang di gunakan dalam sebuah rekayasa web yaitu analisis isi, interaksi, konfigurasi, fungsional dan analisis navigasihubungan. Model desain meliputi tampilan muka, etika, isi, navigasi arsitektur.

\section{Constraction}

Peralatan dan teknologi yang di gunakan untuk membuat sebuah aplikasi website yang sudah di buat modelnya. Dalam pembuatan website ada beberapa yang digunakan diantaranya bahasa pemrograman PHP dan HTML, Apache, database MySQL, editor perangkat lunak. Serangkaian tes dilakukan untuk memastikan tidak adanya kesalahan dalam desain (isi, arsitektur, interface, dan navigasi)

\section{Delivery \& Feedback}

Sistem aplikasi web dikonfigurasikan untuk semua lingkungan yang berhubungan dengan operasionalnya dan dikirimkan kepada penggunanya.

Pelaksanaan kegiatan selanjutnya setelah program di buat, di ujicoba dan di publikasi adalah dengan melakukan sosialisasi dan pelatihan kepada berbagai pihak terkait, seperti:

- Kepala Desa dan Jajarannya di kantor desa Dayeuhmanggung.

- Ketua RW/RT di desa Dayeuhmanggung

- Perwakilan masyarakat/UMKM terkait di desa Dayeuhmanggung

Setelah proses sosialisasi dilaksanakan tahapan selanjutnya adalah proses pedampingan agar program ini dapat berjalan sesuai dengan yang diharapkan dan terakhir adalah monitoring dan evaluasi program 
untuk mendapatkan gambaran tentang keberhasilan program yang sudah dilakukan.

\section{HASIL DAN PEMBAHASAN}

Website desa Dayeuhmanggung merupakan website dinamis dengan alamat link https://dayeuhmanggung.com/. Memiliki beberapa menu yaitu :

1. Home : yang berisi selamat datang dari website tersebut.

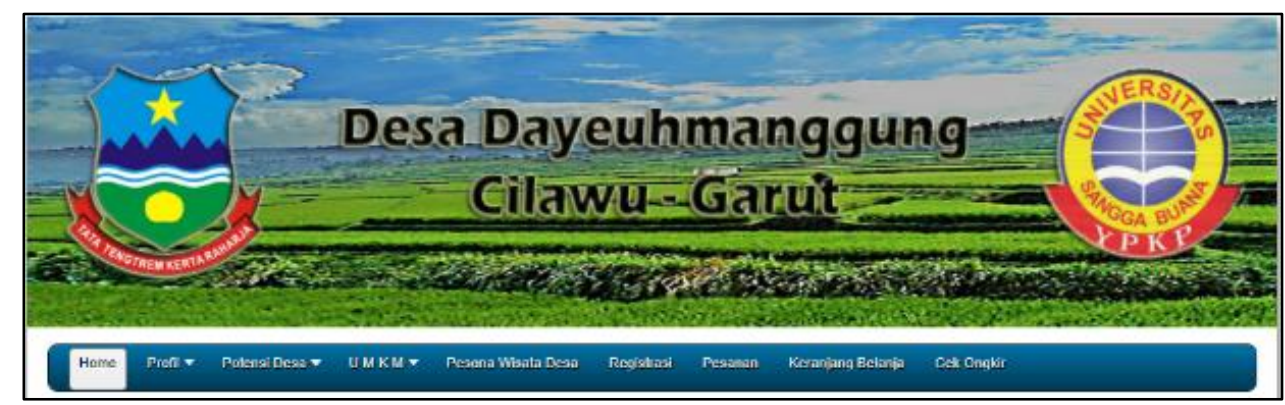

Gambar 3 : Halaman Muka Website

2. Profil : berisi sejarah desa, geografis desa, pimpinan desa, dan

4. UMKM : berisi tentang profil dan lembaga formal desa

3. Potensi desa : berisi semua potensi produk UMKM di desa Dayeuhmanggung yang terdiri dari desa yang menjadi aset dan bisa dikembangkan.

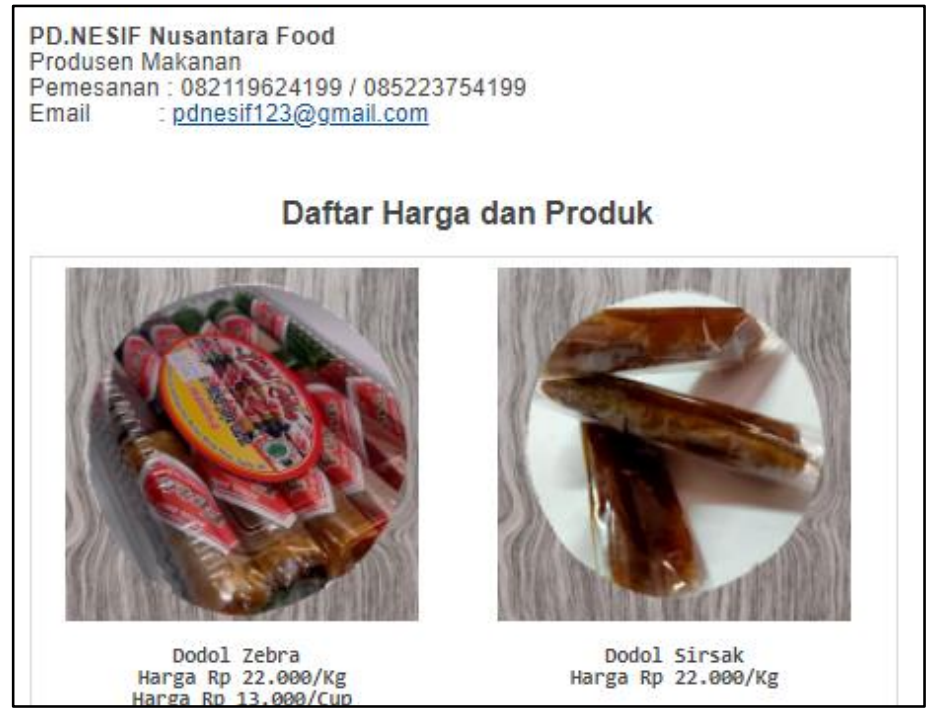

Gambar 4: Profil UMKM dan Produknya 


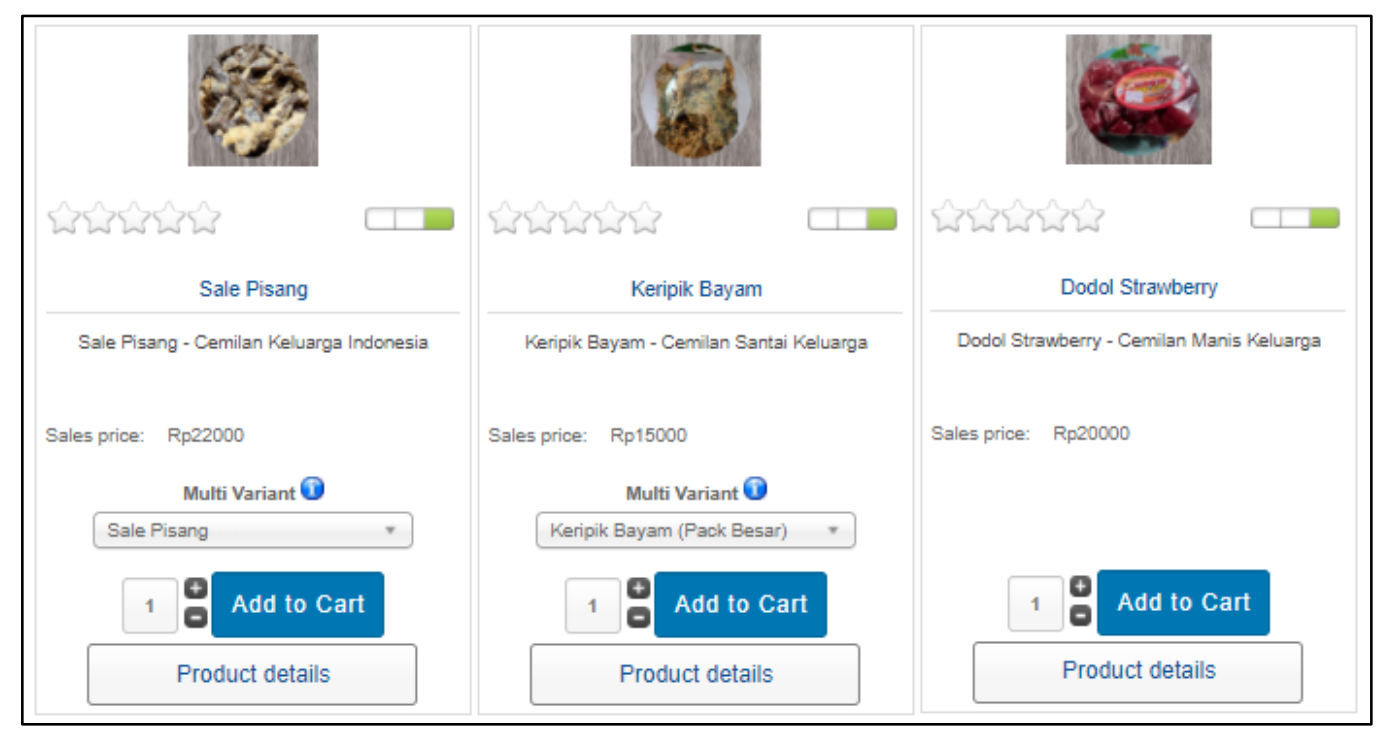

Gambar 5 : Menu Belanja Online di website

5. Pesona Wisata : berisi tentang profil wisata di desa Dayeuhmanggung

6. Registrasi : menu pendaftaran yang disediakan untuk pembeli yang mau berbelanja melalui website

7. Pesanan : daftar pesanan yang telah dipilih dan akan dibeli secara online lewat aplikasi

8. Keranjang belanja : berisi belanjaan yang dipesan oleh pembeli

9. Cek ongkir : berisi link untuk mengetahui biaya kirim dari lokasi UKM ke alamat pembeli.

Para UMKM bisa bekerjasama mempromosikan dan memasarkan produk mereka secara online melalui website ini. Pada gambar 4 terdapat contoh UMKM dan aneka produk yang di jual oleh mereka. Konsumen atau investor bisa menghubungi mereka untuk membeli secara langsung atau melalui website serta bisa menjalin kerjasama bisnis secara langsung.

\section{PENUTUP}

Informasi mengenai potensi desa dan UMKM di desa Dayeuhmanggung dapat disampaikan dan diakses melalui media website secara cepat dan murah oleh masyarakat luas tanpa batasan waktu dan jarak. Masyarakat bisa ikut mempromosikan potensi desa dan UMKM melalui media sosial yang mereka miliki. UMKM dapat mempromosikan, menjual dan menjalin kerjasama dengan para investor dari manapun. Pelanggan dapat memilih dan melakukan pemesanan produk melalui website serta dapat melihat riwayat pesanannya sehingga memudahkan dalam bertransaksi.

Penyebaran informasi mengenai potensi desa dan produk UMKM ini diharapkan bisa meningkatkan pendapatan masyarakat yang secara tidak langsung akan menambah penyerapan tenaga kerja dan meningkatkan pendapatan asli daerah desa Dayeumanggung. Pendampingan dan pembinaan para UMKM secara berkala khususnya oleh perguruan 
tinggi melalui berbagai program kegiatan pengabdian kepada masyarakat sangat penting dan diharapkan oleh masyarakat dalam menyikapi penggunaan teknologi dan persaingan bisnis yang sangat cepat dalam berbagai bidang.

\section{DAFTAR PUSTAKA}

[1] H. T. Fristanto, "Pembuatan Website Promosi dan Pemesanan Produk Pada Home Industri Agro Santoso Jamur Punung Pacitan," Seminar Riset Unggulan Nasional Informatika dan Komputer FTI UNSA, Vol. 2, No. 1, ISSN: 2302-1136, Maret 2013.

[2] Gunawansyah, Peti Savitri; "Pembangunan Sistem Seleksi
Karyawan Secara Online Dengan Metode Simple Additive Weighting," Jurnal Seminar Nasional Informatika dan Aplikasinya (SNIA), ISSN: 23392304), hal 176-181 2013

[3] Abdul Halim dkk, 2012. Akuntansi Sektor Publik Akuntansi Keuangan Daerah. Edisi 4. Penerbit Salemba Empat. Jakarta

[4] Undang-Undang Republik Indonesia Nomor 25 Tahun 1999 Tentang Perimbangan Keuangan antara Pemerintah Pusat dan Daerah, http://www.djpk.kemenkeu.go.id/?p=3 53 (diakses 23 Juli 2021)

.[5] Utaminingtyas,Lestari. "Perangkat Lunak Pendukung Aktivitas Penyampaian Informasi dan Publikasi Berbasis Web", 2000 